\title{
ENTRE A ÁFRICA E A EUROPA: DESLOCAMENTO E FRAGMENTAÇÃO IDENTITÁRIA EM A MENINA ÍCARO, DE HELEN OYEYEMI ${ }^{1}$
}

Denise Almeida Silva (UFRGS)

Diego Bonatti (UFRGS)

Resumo: A literatura pós-colonial, enquanto campo de estudos que investiga os problemas causados pelo imperialismo europeu, tem representado a dificuldade de localização cultural e identitária do sujeito pós-colonial. Nessa perspectiva, o objeto de análise escolhido para este trabalho é $A$ Menina ícaro, da escritora nigeriana-inglesa Helen Oyeyemi. A protagonista, Jessamy, é uma menina negra inglesa, filha de pai inglês e mãe nigeriana. Ela transita entre as culturas inglesa e nigeriana, sentindo-se deslocada em ambas. Assim, elegemos como objetivos deste estudo a investigação das questões de identidade cultural e deslocamento da protagonista em relação à África e à Europa, ressaltando a fragmentação identitária por ela apresentada. Para tanto, buscamos apoio teórico para o estudo de questões como identidade, deslocamento e migrância, principalmente no pensamento de Helena Callai (2004) e Stuart Hall (2005; 2003). Já sobre identidade migrante e fragmentação identitária partimos do pensamento de autores como: Pierre Ouellet (2012), e Sarah llott e Chloe Buckley (2016). Como resultados podemos destacar que: a) Jessamy não tem um lar fixo, já que esse espaço é preenchido tanto pela Nigéria, quanto pela Inglaterra, que têm elementos culturais presentes em sua vida; b) o trânsito entre duas culturas e a falta de vínculos identitários sólidos levam a protagonista à crise identitária; c) como no mito grego de Ícaro, a protagonista é um sujeito em busca do encontro consigo mesma; a tentativa de harmonia com as duas identidades, entretanto, é fato impossível e indefinido no enredo, o que evidencia a complexidade da identidade do sujeito póscolonial.

Palavras-chave: Literatura pós-colonial; Literatura inglesa; Deslocamento; Fragmentação identitária; A Menina Ícaro.

1 Título em inglês: "Between africa and europe: displacement and identity fragmentation in Helen Oyeyemi's The Icarus girl" 
Abstract: Post-colonial literature, as an area of knowledge that investigates the problems caused by European imperialism, has represented the post-colonial subject's difficulty of cultural and identity location. One such novels is Nigerian-born English writer Helen Oyeyemi's The Icarus girl, which is the object of this analysis. Its protagonist, Jessamy, the daughter of an Englishman and of a Nigerian woman, oscillates between English and Nigerian cultures, feeling displaced in both. Thus, the investigation of questions raised by Jessamy's cultural identity and displacement, i. e., her identity fragmentation associated to her sense of belonging in relation to Africa and to Europe, was chosen as the study's objectives. In order to meet these goals, issues around identity, displacement, and migration find support, especially, on the thought of Helena Callai (2004) and Stuart Hall (2005; 2003). Pierre Ouellet (2012) and Sarah Ilott; Chloe Buckley (2016) support the analysis of issues around migrating identity and identity fragmentation. As findings, we can point out that: a) the absence, in the protagonist's experience, of a fixed sense of home, for it is divided between Nigeria and England, both of them present in her life; b) the transit between two cultures, deprived of a steady identity sense, leads the protagonist to an identity crisis; c) as in the Greek myth of Icarus, the protagonist is a subject in search of an encounter with herself; the attempt to harmonize the two identities, however, is an impossible and indefinite fact in the plot, which evidences the postcolonial subject's complex identity.

Keywords: Post-colonial literature; English Literature; Displacement; Identity Fragmentation; The Icarus Girl.

O ser humano tem, de há muito, se movido pelo globo, alcançado novos espaços e, neles, produzido novos hábitos e costumes. Entretanto, essa movência e a relação com outras culturas pode não ser um processo harmônico, mas levar a situações conflitantes, em que o sujeito se vê dividido entre espaços, culturas e ideologias, e a uma crise de identidade. Tal situação é observada na obra A Menina Ícaro, em que Helen Oyeyemi apresenta a história de Jessamy, menina inglesa, negra, 
filha de mãe nigeriana e pai inglês. Jessamy não consegue lidar com a ambiguidade de pertencer à África e à Europa, de viver a tradição nigeriana e a inglesa, de fazer parte de dois mundos tão presentes em sua vida, e tão diferentes.

Elegemos como objetivos de estudo, para este trabalho, a investigação de questões relativas à identidade cultural e deslocamento da protagonista, Jessamy Harrison, tanto em relação à África como à Europa, ressaltando a fragmentação identitária por que passa. Nesse contexto, ganha relevância a verificação de como os conceitos de lar e migrância se apresentam na obra, assim como a análise das ressonâncias da referência mitológica a Ícaro. Inicialmente apresentamos, para benefício do leitor não familiarizado com a obra, uma breve resenha da mesma, e justificamos a perspectiva analítica escolhida dentro do contexto da recepção crítica recebida pela obra. A seguir, enfocamos a relação entre migração e deslocamento no romance, e as implicações do mito de Ícaro com relação ao conflito identitário enfrentado pela protagonista.

\section{A MENINA ÍCARO: UMA PROPOSTA DE LEITURA OCIDENTAL}

A menina Ícaro, romance de estreia da autora nigeriana Helen Oyeyemi, apresenta como protagonista Jessamy Harrison, menina que, já ao início da obra, é apresentada 
como criança histérica, problemática, deprimida e introvertida. Desde muito cedo, passa por uma crise identitária que afeta seu relacionamento com os pais e os colegas. O conflito a faz, cada vez mais, fechar-se no seu mundo em busca do encontro com o seu verdadeiro "eu", na tentativa de descobrir quem ela realmente é. Sua crise se acentua ainda mais quando, na Nigéria, em viagem com os pais para visitar a família da mãe, faz amizade com o espírito de Titiola, menina fisionomicamente igual a ela. Com o passar do tempo, Titiola - ou TillyTilly, como Jessamy prefere chamá-la - começa a se apossar do corpo da menina, obrigando-a a ter atitudes hostis para com as pessoas ao seu redor, e aumentando, dessa forma, sua perturbação. A situação se intensifica ainda mais quando o espírito revela a Jessamy que ela tinha uma irmã gêmea, Fern, que morreu no parto. Nesse ponto da narrativa, toda a família da menina é afetada por seu desequilíbrio emocional e comportamental. Tanto o avô nigeriano, quanto os pais de Jess discutem quanto à natureza do problema: estaria passando por um problema psicológico, ou de ordem espiritual? A questão é especialmente inquietante para o ramo nigeriano da família, dada à crença da mitologia iorubá de que, quando um gêmeo morre, se sua estátua não for ofertada a Ibeji, o deus dos gêmeos, o falecido atormentará a seu irmão vivo. 
Jessamy é levada à Nigéria, com a intenção de cumprir rituais que a libertariam de Titiola, ao que seu pai, cético, se opõe. Em um final enigmático, após um acidente automobilístico em que fica gravemente ferida, Jessamy encontra-se com Titiola e trava uma luta com ela. No final do embate, a menina, ainda entubada no hospital, é descrita como havendo "subido", o que pode evidenciar tanto uma volta à consciência, como sua morte.

Como se vê, a obra tematiza a questão do duplo, e significativa parcela dos trabalhos sobre a mesma tem se centrado na teoria do duplo e sua relação com a espiritualidade de origem africana. Contudo, como Ase Lundell (2010) sugere, a obra possibilita dois modos diferentes de leitura, o ocidental e o africano. O primeiro tem sido pautado por interpretações que se atêm à versão africana do mito do doppelgänger, como na interpretação de Stouck (2011), de acordo com a qual TillyTilly seria um fantasma, ocorrência do mito abiku, em que o espírito de uma criança que morreu se apega ao corpo de outra que permanece viva. Por outro lado, em uma perspectiva ocidental, como Lundell (2010) ainda sugere, a relação de duplicidade pode ser interpretada como uma situação traumática causada pelo conflito cultural, como uma abstração criada por Jess para lidar com o conflito por que passa, ou ainda como um problema psicológico, em que ela teria uma dupla personalidade. 
Neste trabalho optamos por estudar a obra a partir de uma linha de interpretação pautada na perspectiva pós-colonial, e, pois, em um modo de leitura ocidental; privilegiamos a investigação do problema de localização e identidade do indivíduo pós-colonial inserido em contextos migratórios, bem como o deslocamento cultural e físico por ele enfrentado.

Justificamos a associação da obra a um contexto póscolonial uma vez que a crise identitária por que passa a protagonista é inseparável do contexto de diáspora nigeriana na Inglaterra, ou seja, do deslocamento de habitantes de território que integrou o império britânico para aquela que era tida como a pátria-mãe.

A plena compreensão da migração desses ex-coloniais implica que retrocedamos ao início das grandes navegações europeias no século $\mathrm{XV}$, as quais colocaram o europeu em contexto de interação cultural com seus outros. Surgem, então, colônias ultramarinas, cuja posse apoiava-se na visão dos povos colonizados como inferiores, e de seus territórios como não pertencentes a seres humanos, e, por isso mesmo, passíveis de serem dominados pelas metrópoles europeias.

Dentre os países que sofreram com o imperialismo, destacamos a Nigéria, por ser o país natal de Oyeyemi, 
e o país escolhido como a pátria natal da mãe da protagonista de A Menina ícaro. Já por volta da metade do século XIX, a Nigéria estava sob o domínio inglês, sob o qual permaneceu até 1960, quando alcançou a independência (THE COMMONWEALTH, 2017). O país teve sua cultura e sistema de governo influenciados pelos colonizadores, que implantaram o inglês como idioma oficial e exploraram os cidadãos nigerianos por meio do tráfico de escravos para a América, onde eram vendidos e forçados a trabalhar em plantações de cana de açúcar.

Após o fim do tráfico negreiro, muitos cidadãos nigerianos continuaram sob o poder colonial inglês. Mesmo após a independência, nigerianos que haviam nascido e crescido sob o domínio do poder imperial passaram a buscar na Inglaterra, a metrópole que aprenderam a servir e superestimar, o lugar que julgavam ser seu por direito e ao qual julgavamse pertencentes. Tal foi o caso da família da mãe da protagonista de A menina Ícaro, Sarah, a qual, ao se deslocar para a Inglaterra, com o intuito inicial de estudar medicina, acaba conhecendo um inglês, com quem se casa, lançando, assim, as bases do ambiente multicultural vivenciado pela menina. As implicações do distanciamento da terra natal em A menina Ícaro são analisadas a seguir. 


\section{MIGRAÇÃO E DESLOCAMENTO EM A MENINA ÍCARO}

But now take me home. Take me home where I belong. I got no other place to go (Aurora, "Runaway" - 2016)

O contato com um novo lugar é um processo que envolve diversas questões de cunho social, econômico e político, que se não bem resolvidas podem levar o sujeito a se sentir deslocado nos lugares que habita. Sobre esta problemática, Nayyar (2017) explica:

Deslocamento é uma noção chave e um tema comum tantoà literatura pós-colonial, quanto à literatura moderna. Na qualidade de noção crítica, tem a intenção de interpretar a crise de identidade produzida pelo colonialismo ou modernismo. Sujeitos colonizados foram forçados a abandonar ou se separar de sua terra natal, seu lugar primeiro, suas culturas, tradições e línguas. $O$ homem moderno foi separado brutalmente da tradição na qual vinha vivendo por séculos, e se transformou, portanto, em um ser deslocado e dividido. (s/p - tradução nossa) $)^{2}$

Em A menina ícaro, o distanciamento do país natal é representado por duas situações: a primeira é a migração, da Nigéria para a Inglaterra, da mãe da protagonista, Sarah.

2 "Displacement is a key notion and theme that we come across in postcolonial and modern literatures alike. As a critical notion, it aims to interpret the crisis of identity engendered by colonialism or modernism. Colonised people were forced to abandon or dissociate from their motherlands, their first places, their cultures, traditions and languages. Modern man was cut off from the tradition he had been living with for centuries and hence was morphing into a displaced, split subject." (NAYYAR, 2017, s/p) 
Já vivendo em Londres, a mulher casa com um inglês, e dá à luz Jessamy. A segunda é a viagem da menina, com sua família, da Inglaterra para a Nigéria, situação na qual se destaca a inabilidade da garota de sentir-se em casa tanto na Inglaterra, onde nasceu, quanto na Nigéria, berço de sua mãe, e lugar onde mora parte de sua família.

Viagem e migração são dois movimentos de deslocamento que, além de uma instância física, têm profunda significação simbólica, psicológica e histórica. No caso de Sarah, a migração está inserida no contexto de diáspora nigeriana na Inglaterra. Já a viagem, no caso de Jessamy, é um ato de movência que envolve, como Bou registra em seu verbete sobre viagem,

uma certa distância, [...] fora do próprio país. [...] implica o afastamento de um lugar familiar e a exploração de um lugar novo e desconhecido, diferente do lugar de residência habitual. Essa diferença pode ser lida em termos de enriquecimento e conhecimento do Outro em novas culturas, ou como ameaça, ou, ainda como enriquecimento para a própria identidade. (2016, p.337)

Habitar o novo lugar aonde chega através da viagem é um processo extremamente complexo para a protagonista. $\mathrm{Na}$ Nigéria, tem contato com uma nova cultura, novas formas 
de pensar, interagir e se integrar na sociedade. Nessa oportunidade, também, a protagonista encontra uma parte da sua história pessoal com a qual nunca tivera contato. A vivência da ancestralidade nigeriana é um processo que traz muitos conflitos para a protagonista, tanto de ordem identitária, quanto de pertencimento. Ao se afastar do lugar com o qual estava acostumada, e chegar a um ambiente estranho, Jessamy experiencia sentimento de deslocamento, sensação de incompletude e inabilidade de pertencer ao novo ambiente.

Quando Sarah sai da Nigéria e vai para a Inglaterra, tem a missão de estudar medicina, conforme espera seu pai, Gbenga Oygbebi. Entretanto, estuda Literatura Inglesa, torna-se escritora e casa-se com um inglês, fato que causa conflito entre pai e filha:

Literatura inglesa! Que emprego pode se arranjar na Nigéria que exija o conhecimento de todas essas palavras inúteis? [...] Palavras que descrevem gente branca, coisas brancas, cada história criada em algum lugar onde nós não existimos..." (OYEYEMI, 2006, p.29).

O conflito entre culturas destacado acima se repete ao longo de toda a narrativa. O pai não aceita que Sarah se distancie da tradição nigeriana, que se afaste da cultura, da vida e dos princípios que tinha quando lá vivia. Ao contrariar 
o pai, Sarah vai em busca de seus sonhos, mesmo que para isso tenha que receber questionamentos sobre a validade de sua profissão, que, afinal, para Oygbebi não tinha utilidade, ao contrário da medicina. O pai de Sarah sente-se, de certa forma, traído, já que a filha deixa de lhe ser obediente e observar os costumes nigerianos, e passa a viver conforme a cultura inglesa, valorizando, dessa forma, o modo de pensar do antigo colonizador.

A filha de Sarah, Jessy, ${ }^{3}$ logo no início da narrativa, mostra-se uma criança em conflito. Parece agir de forma diferente do que é esperado para uma menina de oito anos: passa tardes inteiras escondida em armários, brincando sozinha, frequentemente deprimida; ao mesmo tempo em que lê histórias infantis, lê Shakespeare e escreve poemas. Ao perceber o constante estado deprimido da filha, Sarah propõe uma viagem: "- O que acharia de nós irmos à Nigéria?" (OYEYEMI, 2006, p.10). A menina aceita e, junto com o pai, Daniel, e a mãe, desembarca no país africano. Como forma de prevenir o leitor que algo ruim estava por vir, o narrador onisciente lança o seguinte comentário logo após o convite: "'Mas, se soubesse o problema que isso criaria, teria gritado "Não!"... Porque tudo COMEÇOU na Nigéria..."” (OYEYEMI, 2006, p.10).

3 Na obra, a protagonista é chamada alternadamente de Jessamy, Jess e Jessy; os dois últimos correspondem a apelidos usados no contexto familiar. Neste estudo, optamos por usar seu nome, Jessamy, e apenas um de seus apelidos, Jessy, por representar, como llott e Buckley (2016) registram, a posição intermediária entre a identidade dada pelo nome original, e o último apelido. 
Jessamy era, de fato, uma criança problemática. Além de ser conhecida pela introspecção e reclusão em casa, na escola, com os colegas, era famosa também por suas crises de histeria. Um desses muitos ataques acontece durante a viagem para a Nigéria, dentro do avião. Ao perceber os olhares dos outros passageiros sobre ela, e por não saber como reagir diante da situação, nem conseguir parar de olhar, Jess se desespera, grita, e se joga no chão da aeronave. Credita o comportamento ao lugar para onde se desloca: "Era a Nigéria. Esse era o problema. A Nigéria era feia. Ni. Gé. Ri. A." (OYEYEMI, 2006, p.13). Ficam evidentes a ambiguidade e, de certa forma, o receio que ela sente pelo novo país. Ela, que incialmente, aceitara o convite da mãe para fazer a viagem, agora sente repulsa e raiva em relação à terra natal da mãe, atitude que demostra o medo que sente por desconhecer esse país.

O distanciamento da Inglaterra e a aproximação da Nigéria assinalam a ruptura com a concepção de lar tida por Jessamy. Ao afastar-se da Inglaterra, tem seu conceito de lar estremecido, questionado. Essa é uma problemática frequente na vida do sujeito pós-colonial. Para ele, "[...] ao contrário do apego ao aqui ou ao lá, o lar é concebido como pertencendo a mais de uma localidade simultaneamente" (SILVA, 2016, p.39). 
A chegada a um lugar completamente desconhecido causa, na protagonista, um misto de emoções. Sai da Inglaterra e chega a um país estranho, acerca do qual tudo o que conhecia eram as histórias ouvidas de sua mãe. Como boa observadora dos detalhes do cotidiano, de imediato começa a comparar esses dois espaços. Ela "[...] não imaginava que fizesse tanto calor na Nigéria" (OYEYEMI, 2006, p.15). Também, reflete sobre outras diferenças, agora de cunho social, quando observa a estranheza causada pela presença de um homem branco num país onde a população negra é majoritária:

O pai estava junto à esteira, as mãos nos bolsos, vigiando as malas. Outra coisa que não imaginava: ela não imaginava que ele fosse parecer tão... bem, deslocado. Ele tinha a cara molhada de suor e vermelha, e até sua postura o diferenciava dos outros. Toda aquela gente aglomerada em volta dele, quando passava, o olhava ostensivamente, eram olhares mais demorados que o normal sem ser diretos... (OYEYEMI, 2006, p.15).

A estranheza não se dá apenas por aspectos físicos, mas também pelo contraste entre as culturas. Ao observar o texto, percebemos que a Nigéria é descrita com características muito diferentes da Inglaterra. Lá as pessoas falavam alto, riam, tocavam-se enquanto falavam. Já na Inglaterra de Jess “[...] a pessoa desviava a vista, sorrindo constrangida 
se o outro lhe devolvesse o olhar ao ser olhado" (OYEYEMI, 2006, p.19). Diante do exposto, tanto Jess quanto seu pai sofrem um choque cultural em sua chegada. Esse choque é evidenciado à medida que pai e filha começam a interagir com o ambiente africano: ainda no aeroporto, a família é cercada por um grupo de taxistas que, aos berros, oferecem seus serviços a eles, maneira de agir muito diferente da dos ingleses. Observam, ainda, que lá, o trânsito é caótico. Nem o pai nem a filha falam o iorubá, uma das línguas oficiais da Nigéria, o que faz com que se sintam ainda mais deslocados. Sarah, por outro lado, retorna ao lar. Interage com todos a sua volta com muita naturalidade, sorri o tempo todo, fala alto, ri.

A atitude de Sarah demonstra o poder simbólico do pertencimento de um indivíduo em relação a algum lugar. Nos termos deste estudo, define-se lugar como um espaço de experiências, no qual o ser humano interage com outros e se concebe (CALLAI, 2004, Apud RODRIGUES, 2016). Assim, o lugar se torna uma parte fundamental, junto da cultura, para a construção da identidade, haja vista que é um dos principais elementos com o qual as pessoas se identificam, e por meio do qual se sentem pertencentes.

É justamente porque as vivências da infância e juventude ressoam em si que a mãe de Jessamy age como alguém que se sente em casa. Ao agir assim, exterioriza um sentimento 
de pertencimento, o qual, como Silva (2016) descreve no contexto de sua definição de casa/lar, pode se manifestar de diferentes formas, sendo a mais comum com relação ao conceito de lar. Cabe aqui uma ressalva: lar não se confunde com casa, que pode aludir apenas à construção física, mas diz respeito a um determinado contexto ou espaço de afeto ao qual o indivíduo se liga por laços afetivos.

Sentir-se bem com relação ao lar reflete-se nas atitudes do sujeito. Quando em seu espaço natural, ou em novo lugar com o qual se sinta pertencente, o ser humano age com naturalidade, interagindo com o ambiente e com outros indivíduos sem medo ou qualquer dificuldade. Todo o afeto que liga Sarah à Nigéria, e a espontaneidade de seus atos, não é algo compartilhado por sua filha.

Para Jess, a Nigéria é um ambiente desconhecido, e o primeiro contato com a família nigeriana é outro momento de tensão para a menina. Ao chegar à casa do avô, relembra tudo o que sua mãe dissera sobre ele, sobre ser rígido, e sobre gritar, por isso se mantém tímida no momento do encontro. Após, no primeiro momento a sós com o avô, na sala, Jess "[...] o olhava de olhos arregalados (...). Sentiu que estava à beira de um ataque de gritos... Ele não era nada parecido com o seu avô inglês. Era... uma pessoa, alguma coisa, diferente, mas escondida" (OYEYEMI, 2006, p.24). 
Ao buscar no avô nigeriano as características que conhecia do avô inglês, inconscientemente a protagonista estabelece uma relação de diferença, tomando o ambiente inglês como natural, isto é, originário. Ao comparar os seus dois avôs, Jess tenta encontrar alguma semelhança que a faça se sentir próxima do avô nigeriano, e gostar dele, sentimento que é despertado aos poucos durante a visita.

Numa certa ocasião, após ter convivido por certo tempo com a família e com a cultura local, Jess é questionada por tia Funke se ela estava gostando do país, pergunta que a protagonista devolve com um silêncio constrangedor: "[...] Não podia dizer muito sobre ela mesma, nem se estava ou não gostando da Nigéria, porque, até agora, não sabia nada de nada" (OYEYEMI, 2006, p.25).

Chegamos a um ponto crítico: qual é, na verdade, o lar da menina Jessamy? Ela pertence ao lar do pai, a Inglaterra, ou ao lar da mãe, a Nigéria? Apesar de ser cidadã europeia, Jess é filha de uma africana: foi criada por um casal com culturas diferentes, e com localizações identitárias diferentes. Cresceu ouvindo histórias e costumes da Nigéria, escutou sua mãe misturar palavras e expressões do iorubá com o inglês, tais como: "[...] Isso é iro ati buba" (OYEYEMI, 2006, p.12). Por outro lado, conviveu desde sempre com o pai, 
um típico cidadão britânico - um homem calmo e ponderado, que a faz interagir com a Inglaterra e sentir-se natural e pertencente àquele ambiente. Assim, tem ligação afetiva com os dois lugares, embora, quando esteja em apenas um deles, sinta-se deslocada e incompleta.

Durante a estadia da família na Nigéria, a protagonista tem diversas oportunidades de contato com a cultura local: é apresentada aos tios, primos, vai ao zoológico, interage a seu modo com os que estão ao seu redor. Numa dessas oportunidades, ao passear pela propriedade do avô, Jess se depara com uma construção antiga e abandonada, o Alojamento dos Rapazes, que antigamente costumava ser habitado pelos vários empregados, homens, da propriedade. De relance, vê uma luz acesa na construção abandonada, fato que desperta sua curiosidade.

Dias depois, decide entrar no alojamento para ver se havia alguém morando lá. Depois de vasculhar a construção, encontra palavras rabiscadas na poeira da mesa: "OlÁ JESSY" (OYEYEMI, 2006, p.41). Desesperada, e chorando, corre dali; no caminho encontra os primos, mas eles não a entenderiam "Porque eles eram garotos, porque eram seus primos, porque o lugar deles era ali e o dela não?" (OYEYEMI, 2006, p.42). Nessa passagem, Jess indica que não 
se sente pertencente, em contraste com seus primos, que nasceram e cresceram ali. Diante disso, questiona-se: seria o fato de nascer em determinado local e vivenciar a cultura daquele espaço o elemento essencial para alguém sentirse pertencente ou não a ele? Na visão de Jess, a resposta parece ser afirmativa, embora observemos que ela também não se sente totalmente ligada à Inglaterra, sua terra natal.

Mais tarde, num outro momento, enquanto estava deitada no chão, Jessamy percebeu que "[...] uma menina estava acima dela, olhando-a com olhos apertados e escuros..." (OYEYEMI, 2006, p.44). Essa menina era "[...] magra, e tinha o cabelo farto [...] Estava descalça e tinha os pés ruços de andar no cascalho e na areia [...] Seu vestido era um pouco grande demais para ela ..." (OYEYEMI, 2006, p.45). Depois de um diálogo em que uma repetia as perguntas da outra, a menina finalmente responde ao questionamento de Jess e se apresenta: “- Meu nome é Titiola" (OYEYEMI, 2006, p.46). As duas se tornam amigas, e a partir daí coisas estanhas começam a acontecer na vida de Jess, tal como a invasão no escritório do avô pelas amigas, a fuga para visitar o parque de diversão, e o roubo de velas que, misteriosamente, apareciam no alojamento.

Ao regressar para a Inglaterra, Jessamy anseia por rever a amiga nigeriana. Ela "[...] Passava horas trançando uma 
pulseira especial de amizade para TillyTilly com o trançado mais minúsculo possível, depois desmanchava e recomeçava porque as cores estavam todas erradas." (OYEYEMI, 2006, p.77). É possível perceber que o contato com outra cultura, com outro país, e o encontro de uma amizade naquele lugar causam, em Jess, uma mudança. Ela busca a nova amiga e se isola, cada vez mais, do mundo exterior a ela. A adaptação na escola fica mais difícil, já que ela tinha avançado uma série por já saber ler e escrever perfeitamente; os ataques de nervos se tornam mais frequentes.

Jessamy parece experimentar um processo de transformação semelhante ao que é muitas vezes sentido pelo sujeito migrante. De acordo com Rocha (2010), o contato com novas culturas coloca o sujeito migrante em uma situação de mudança. Nesse novo lugar em que passa a viver, é posto diante de desafios e situações que podem levá-lo a entrar em conflito com a cultura e o modo de pensar herdados da terra de origem. Como consequência, "[...] o migrante é levado a interagir e, não raramente, a assumir, muitas vezes, de forma inconsciente, a maneira de pensar do novo contexto sociocultural" (ROCHA, 2010, p.241). Essas novas formas de pensar, agir e conviver com outras culturas podem desencadear o surgimento de novas relações culturais e sociais. 
Neste contexto, o deslocamento causado pelo contato da menina com a cultura nigeriana se agrava de tal forma que traz consequências de cunho identitário para ela. Jessamy está tão deslocada, tão dividida entre dois mundos, que a relação ambígua com os dois países e as duas culturas a leva a questionar a própria identidade e se ver diante de uma encruzilhada: ser branca ou ser negra? Ser europeia ou africana? Falar inglês ou iorubá? É sobre esse conflito identitário que discorreremos a seguir.

\section{EUROPEIA OU AFRICANA: QUEM É A MENINA ÍCARO, AFINAL?}

Voar voar, subir subir ir por onde for Descer até o céu cair ou mudar de cor

De querer sentir o que eu não posso ter $O$ que faz de mim ser o que sou É gostar de ir por onde ninguém for (BYAFRA, "Sonho de Ícaro", 1984)

Para refletir sobre a identidade da protagonista, revisamos o próprio conceito de identidade e refletimos, ainda, sobre o título da obra. Como é sabido, a identidade "[...] é realmente algo formado, ao longo do tempo, através de processos inconscientes, e não algo inato, existente na consciência no momento do nascimento" (HALL, 2005, p.38). Um mesmo indivíduo pode adotar diferentes "[...] posições de sujeito" (HALL, 2005, p.17), e, portanto, mais do que uma identidade cultural. Estas, associadas a diferentes contextos sociais 
e temporais, podem, por vezes, ser "[...] contraditórias ou não resolvidas" (HALL, 2005, p.12). Dessa forma, a afirmação da identidade é processo mutável, e mediado pela interação cultural, abarcando múltiplas vivências e trânsitos.

Como se viu na seção anterior, a trajetória de Jessamy Harris é marcada por deslocamentos que influenciaram profundamente sua formação identitária. A indagação

que subjaz a seu conflito identitário é, essencialmente, a tentativa de compreensão de quem realmente é. Tal compreensão passa, como já registrado, pela oscilação entre a aceitação e interiorização da cultura inglesa e da africana, e problematiza-se a partir da possibilidade de conciliar, ou não, essas duas culturas.

No contexto dessa oscilação cultural, chama a atenção o fato de que Oyeyemi optou por nomear a obra - e, por extensão, sua protagonista - A menina ĺcaro, nome que remete ao bem conhecido mito grego, e revela algumas características de Jessamy. Ícaro é filho de Dédalo, grande inventor e escultor de Atenas, personagem mitológico que representa a engenhosidade humana e que tem, na construção do Labirinto, uma de suas obras mais conhecidas. A construção se faz a pedido do rei Minos, para aprisionar - Minotauro, oriundo da traição de sua esposa Pasífae com um touro. Contudo, após ajudar Ariadne, a filha do rei 
Minos, a fugir com Teseu, o filho do rei de Atenas, Dédalo é castigado pelo rei Minos e, como punição, jogado no Labirinto, junto com seu filho Ícaro, em prisão perpétua. Face à impossibilidade de escapar por terra ou mar, Dédalo concebe a ideia de fugir pelo ar: junta penas de aves, e colaas com cera de abelha, criando dois pares de asas. Na fuga, recomenda a seu filho ícaro não voar tão alto para que não derretesse a cera das asas, nem tão baixo que a umidade da água do mar fizesse com que as penas pesassem e, como consequência, provocassem sua queda. Entretanto, durante o voo, Ícaro deslumbra-se com a possibilidade de voar e chega tão alto que as asas derretem, e ele cai no mar, onde morre (BULFINCH, 2002; BRANDÃO, 1986; DANIELS, 2016).

No título da obra analisada, Ícaro passa de um nome próprio a um adjetivo. Ao ser comparada com este personagem mitológico, é razoável afirmar que a protagonista tem algumas características reveladas, tais como a criatividade, a imaginação, a simbologia da fuga empregadas pelas asas, a busca pela liberdade e o sonho. Jessamy, assim como Ícaro, está à procura de um lugar, de uma localização, de uma identidade, algo que lhe permita se afirmar e se reconhecer. Contudo, o processo de interação de culturas tão distintas a leva a uma crise identitária, que é representada de maneiras diferentes pela escritora Helen Oyeyemi. 
Pode-se observar, por exemplo, já no nome da protagonista: Jessamy é o seu nome inglês, escolhido por seus pais; todavia, seu avô, Gbenga Oygbebi, ao seguir a tradição iorubá, escolhe um nome diferente para a menina, que na Nigéria seria chamada de Wuraola. Ao ouvir pela primeira vez o nome,

Ela ficou paralisada, sem saber o que dizer ou fazer.

[...] mas ninguém jamais a chamara de Wuraola, nem mesmo sua mãe...

[...] Aqui, nesse corredor murado de pedra onde a luz entrava por enormes telas de mosquito colocadas em cada janela e suas roupas the grudavam no corpo como uma segunda pele, Wuraola parecia outra pessoa. Nada a ver com ela.

Será que devia atender a esse nome, e, ao fazer isso, roubar a identidade de alguém dali?

Será que devia tornar-se Wuraola? (OYEYEMI, 2006, p.22-23 - Grifo original)

Fica explícito o conflito identitário pelo qual passa a protagonista ao ter sua identidade inglesa estremecida. A adoção de um novo nome, neste caso, implica a afirmação de uma nova identidade pela protagonista, fato que a amedronta e a deixa instável. O nome de alguém é parte 
essencial de sua identidade. Diz muito sobre a cultura em que está inserido, assim como diferencia seu portador e o torna único perante os demais. Ao contrário da protagonista, que se sente insegura e receosa ao adotar a nova identificação, sua mãe, Sarah demonstra não ter problemas ao ser chamada de Bisi, seu nome nigeriano. Curiosamente, ao adotar a Inglaterra como novo país, Bisi passa a se chamar Sarah, assumindo, assim, novas instâncias em sua identidade, pois na Inglaterra ela deveria se comportar e agir de acordo com a cultura local.

Outro fato que soma para o conflito cultural-identitário da protagonista é o tipo de tratamento que recebe dos pais. Por várias vezes, em situações críticas, ou quando surgem problemas, a maneira de agir do pai, Daniel, caracteriza-se por abordagem calma, dialogada e compreensiva. Por outro lado, a mãe já é mais enérgica, rígida e, de certa forma, ríspida. Essas duas maneiras diferentes de lidar com os problemas da filha causam até conflitos entre o próprio casal, que diverge quanto à forma correta de educação da menina, fato evidenciado, por exemplo, em um episódio em que a menina tem uma de suas crises. Jess grita desesperadamente; sua mãe a segura pelos ombros e começa a sacudi-la. Ao ouvir as objeções do pai, Sarah dispara “- Cale a boca! Cale a boca! 
Cale a boca!" (OYEYEMI, 2006, p.191). Depois, arrasta a menina até o porão e a aprisiona lá para que se acalme. A menina continua gritando, e pede socorro ao pai, que não aguenta ouvir o desespero da filha e a forma escolhida pela esposa para resolver a situação: "- Sarah, deixe a menina sair. Você já provou o que queria provar" (OYEYEMI, 2006, p.192), ao que a mulher responde: “ - Ela não terminou o ataque" (p.192). Situações como essa aumentam, ainda mais, o conflito na família.

De volta à Inglaterra, Jessamy passa a se comportar cada vez pior, fica cada vez mais difícil de lidar. Na escola, ouve piadas dos colegas e provocações, tais como: "-Talvez Jessamy tenha esses ataques todos porque não consegue decidir se é branca ou preta!" (OYEYEMI, 2006, p.83). Além de ter que enfrentar o racismo por parte dos colegas, necessita encarar seus próprios medos, sua dificuldade de interação, sua adaptação na nova turma, e sua dificuldade em fazer as pessoas acreditarem na existência de Titiola, quando esta passa a perturbá-la na Inglaterra.

Ante o comportamento cada vez mais difícil da menina, os pais decidem levá-la a um psiquiatra, na tentativa de entender o que se passa com ela. Entretanto, coisas estranhas continuam a acontecer, tais como a mudança repentina de comportamento, o acontecimento de fatos sobrenaturais, 
e improváveis. Com o passar do tempo, Jess acaba por "[...] perceber com uma clareza espantosa que era a única pessoa que via TillyTilly.[...] Jess de repente sentiu-se muito pequena e meio assustada. TillyTilly é... real? (OYEYEMI, 2006, p.83)

Isso causa diversos atritos entre Jess e seus pais, que não acreditam nas estripulias feitas pela "suposta" amiga. Também a relação entre a mãe e a filha é conflituosa. Como ambas têm uma personalidade forte, com frequência se desentendem. Apesar disso, Jess sofre grande influência da mãe: lê Shakespeare, não tem bonecas Barbie, nem mesmo as negras, devido ao estereótipo de beleza muito criticado pela mãe. Ao falar sobre a mãe numa consulta com o psicólogo, Jess revela: “[...] - Às vezes tenho a sensação de ela quer que eu... Sei lá. Ela quer que eu seja nigeriana. E eu não quero ser modificada assim; não posso ser. Pode machucar" (OYEYEMI, 2006, p.243). O medo de ser alguém diferente, de assumir, ou de agregar uma identidade nova causa, na protagonista, o maior dos conflitos: ser Jessamy, ou ser Wuraola? Quem é ela?

O ápice do conflito identitário sofrido pela menina pode ser percebido, também, na forma como a sua mãe lida com o problema do pertencimento: “- Jess, não se trata de eu querer que você seja nigeriana, você é, simplesmente é! [...] -É inglesa também. Está tudo bem" (OYEYEMI, 2006, p.243). 
Mas nada é tão simples assim, Jess não está bem e sofre, incapaz de escolher uma só pertença: “[...] seria inglesa. Não, não podia, porém. Seria nigeriana. Não..." (p.243).

Outro momento da narrativa que evidencia essa indecisão é quando a menina convida a prima inglesa, Dulcie, e Siobhan, a filha de seu psiquiatra, para uma festa do pijama. Naquela noite, Sarah e uma amiga fazem sonhos na cozinha, e comentam que os doces feitos por Dulcie são melhores do que os de Jessamy. "-Talvez você seja meio africana por associação" (OYEYEMI, 2006, p.210), a sra. Coker, a amiga de Sarah, justifica, associando, assim, Dulcie à tradição culinária da terra de Sarah. Surpreende, nessa ocasião que Jessamy reclama para si a reivindicação da nacionalidade nigeriana: "- Mas eu sou a nigeriana [...] você não pode falar sobre isso" (OYEYEMI, 2006, p.210 - grifos originais). Assim a menina alterna sua identidade: por vezes se afirma nigeriana, por vezes nega sua ascendência africana; em outros momentos é inglesa, e assim sucessivamente, evidenciando, mais uma vez, o problema de localização identitária por que passa.

A indecisão entre adotar uma ou outra identidade, ou seja, a divisão entre o lugar do sujeito e o lugar ocupado pelo Outro é, de acordo com Ouellet (2012), uma situação comum na pós-colonialidade. Conforme o teórico, a migrância e a adoção de novos espaços têm ocasionado o surgimento de 
indivíduos divididos entre lugares, que se sentem deslocados tanto no novo contexto quanto no local original, uma vez que não conseguem, ou não podem pertencer por inteiro a nenhum deles (OUELLET, 2012), partilhando, simultaneamente, mais do que um território e uma história.

Em uma segunda ocasião em que a família Harrison visita a casa do avô Gbenga Oygbe, Jess já fala iorubá, o que demonstra sua aproximação com as raízes de sua mãe. Por outro lado, está sendo perturbada por Titiola que, agora, já se apossa de seu corpo. O conflito, nesse sentido, é maior do que na primeira visita.

Ao tomar conhecimento sobre o que se passa com Jess, e de como ela havia descoberto sobre Fern, sua gêmea que morreu, o avô decide levá-la a uma feiticeira para resolver o problema, o que causa uma briga entre o sogro e Daniel. O casal decide ir para Lagos, a capital da Nigéria, onde reside o irmão de Sarah. No entanto, no trajeto da casa do avô até o destino, o carro ocupado por Jess capota, e a menina se encontra com TillyTilly. Jess escuta seu nome africano sendo chamado Wuraola. Quando o espírito do seu duplo corre em sua direção, Tilly Tilly implora para que isso não aconteça. Mesmo assim, decidida, Jess segue seu caminho; as duas se engalfinham e se enfrentam. Ao final do confronto, Jessamy "[...] subiu e subiu e subiu à consciência" (OYEYEMI, 2006, p.301). 
Essa subida tem significação ambígua, e pode ser tanto a subida ao mundo espiritual, quanto o regresso à consciência, deixando, portanto, o final em aberto, especialmente se considerado o texto do original inglês:

she clawed at Jess's presence

(it hurt them both burningly)

$$
\begin{aligned}
& \text { back into } \\
& \text { Jessamy Harrison woke up and up and up } \\
& \text { and up. }
\end{aligned}
$$$$
\text { (OYEYEMI, 2006b, p.175) }
$$

O texto deixa, assim, um final com dupla interpretação: ela pode ter saído do coma e resolvido seu problema identitário, ou subido ao mundo espiritual, isto é, morrido. Nesse caso, o problema identitário não foi resolvido, uma vez que o duplo se mantém.

Mais uma vez, a indefinição se torna central na narrativa. O fato de a protagonista ter um final ambíguo, passível de mais de um tipo de leitura parece associar-se a sua condição de sujeito pós-colonial, fruto da relação entre colonizador e colonizado, que se encontra numa posição indefinida, tanto cultural quanto identitariamente.

Lendo essa cena de uma maneira mais simbólica, podemos indicar a impossibilidade de resolução do problema de identidade, e sua perpetuação. Ao transitar entre lugares, 
culturas e identidades, Jessamy acaba por se localizar em uma espécie de "lugar nenhum", um espaço metafórico que representa o trauma e a cisão irremediável causada pelo colonialismo.

\section{CONSIDERAÇÕES FINAIS}

O preço por sonhar demais, por se deslumbrar com o voo e com a possibilidade de alcançar novos lugares foi pago a um alto preço por Ícaro e seu pai. Depois de ter realizado um grande feito, Dédalo foi punido severamente, e lançado à morte em uma prisão intransponível. Ao tentar uma fuga arriscada, Dédalo traçou uma linha tênue entre o possível e o impossível, a qual seu filho Ícaro transgrediu. Sarah, ao sair da Nigéria, foi punida com a repressão de seu pai, que se sentia traído por ela. Sarah reside, agora, em um país estrangeiro, junto à filha que sofre por não saber quem é, nem sabe como lidar com o fato de pertencer a dois mundos e duas culturas diferentes. A solução encontrada pela mãe para dar fuga aos sentimentos da filha foi a do regresso à Nigéria, a fim de fazer com que ela se encontrasse ao conhecer suas origens.

Jessamy, por sua vez, sonhadora, imaginativa e deslumbrada como ĺcaro, chega, da mesma forma, muito perto do sol, isto é, chega muito perto de um feito extraordinário e improvável, que, em seu caso, seria a resolução 
do problema identitário. Tanto a chegada à estrela central do sistema solar por meio de um par de asas artesanais, como a resolução simples de um problema de ordem indentitária são feitos impossíveis. Primeiro porque chegar ao sol dessa forma é fisicamente irreal; segundo, porque a identidade não é algo que se possa mudar em um piscar de olhos, mas é o resultado de convivência social e, portanto, um processo histórico, construído ao longo do tempo, e que depende da elaboração individual com referência à integração dos modos com que um sujeito é chamado a agir em cada uma de suas identidades culturais, um processo bastante complexo para uma menina de oito anos.

Entretanto, apesar de aproximarmos nossa leitura do final da obra ao que Lundell (2010) chama de "leitura ocidental", é impossível afirmar que o sonho de liberdade e de encontro da protagonista com a própria identidade é trágico. Sobre essa indefinição do que realmente acontece com a personagem, Ilott e Buckley (2016) encontram um valor simbólico: “[...] Esta não é a afirmação escrita de identidade, mas sim a revelação da falha nela contida"4 (p.413), bem como a constituição de um "[...] contínuo processo do tornar-se" ${ }^{5}$ (p.414).

Nessa perspectiva, a identidade, enquanto processo em conflito na narrativa, é um dos pontos de maior tensão

\footnotetext{
4 [...] This is not the affirmation of a written identity, but the revelation of its failure.

$5 \quad[\ldots]$ continued process of becoming.
} 
observado. Como nos lembra Hall (2003), no contexto de uma sociedade que passou por processos coloniais, mais especificamente em contextos diaspóricos, é possível observar o surgimento de identidades ou subjetividades múltiplas, que não mais se referem a um lugar ou cultura específicos, mas à localização que conserva traços do espaço original, ao mesmo tempo em que agrega características da nova cultura com que é mantido contato.

Dessa forma, a menina entra em conflito ao não saber qual posição de sujeito adotar: a de ser filha de um homem branco, ou de uma mulher negra, de um inglês ou de uma nigeriana, de uma cultura marcada pelo ponderamento ou de uma reconhecida pela espontaneidade, de falar inglês ou iorubá, de sentir frio ou calor, de ser europeia ou africana. Diante desse paradoxo, Jessamy passa a agir tendo duas instâncias identitárias em seu ser: ela é tanto africana, quanto europeia, embora neste processo de fusão e interação das culturas entre em colapso, passando por forte crise identitária e não sabendo, na verdade, quem é. Destaca-se o fato de a protagonista entrar em colapso a partir do momento que tem contato com os outros "eus", exteriores a ela, como Titiola, e interiores, tais como o fato de ser mestiça, portanto, nem completamente branca, nem completamente negra, nem europeia, nem africana, mas ambas. 
A protagonista não se sente pertencente por completo nem à Nigéria, nem à Inglaterra, apesar da grande influência de seus pais. Seu lar é, na verdade, composto pelos dois lugares, que se complementam, cada qual com características específicas, que têm em comum elementos culturais que podem ser identificados na construção da personagem, tais como a sensibilidade britânica e a africana.

Pode-se afirmar, então, que, a identidade de Jessamy é um processo marcado pela influência de aspectos sociais e históricos conflitantes. A inserção num contexto familiar com culturas divergentes, e a movimentação entre dois países de culturas discrepantes é fato que causa conflito na menina, e que a leva a uma grave crise identitária, à medida que experiencia um forte sentimento de não pertencimento e deslocamento, face à inexistência de vínculos identitários fortes com ambas as localidades.

Tal como no mito de Ícaro, a protagonista é um sujeito em busca do encontro consigo mesma; a viagem e a aproximação do sol, assim como a tentativa de harmonia com as duas identidades, entretanto, é fato impossível e indefinido no enredo, o que evidencia a complexidade da identidade do sujeito pós-colonial.

Por fim, destacamos o fato de Jessamy não ter um lar fixo, já que esse espaço é preenchido tanto pela Nigéria, quanto 
pela Inglaterra, que têm elementos culturais presentes em sua vida. Isto localiza, portanto, a protagonista, tanto em termos culturais, quanto identitários, em um entrelugar com relação à África e à Europa, resultado da interação desses espaços.

\section{REFERÊNCIAS}

AURORA (2016). Runaway. Vagalume. In https://www.letras.mus.br/ aurora/runaway/ Acesso em 22.Mar.2018.

BOU, Enric (2016). "Viagem". In: COSER, Stelamaris. (Org). Viagens, deslocamentos, espaços: conceitos críticos. Vitória: EDUFES. p.336-347.

BRANDÃO, Junito de Souza (1986). Mitologia grega. v.I. Petrópolis: Editora Vozes. In https://bibliotecaonlinedahisfi.files.wordpress.com/2015/03/ mitologia-grega-vol-1-junito-de-souza-brandc3a3o.pdf Acesso em 25.Jan.2018.

BULFINCH, Thomas (2002). O livro de ouro da mitologia: (a idade da fábula): histórias de deuses e heróis. 26.ed. David Jardim Júnior (Trad.). Rio de Janeiro: Ediouro. In http://filosofianreapucarana.pbworks.com/f/ O+LIVRO+DE+OURO+DA+MITOLOGIA.pdf Acesso em 25.Jan.2018.

BYAFRA (1984). "O sonho de Ícaro". Vagalume. In https://www.vagalume. com.br/byafra/sonho-de-icaro.html Acesso em 18.Jan.2018.

CALLAI, Helena (2004). "O estudo de lugar como possibilidade de construção da identidade e de pertencimento". In: Congresso Luso-AfroBrasileiro de Ciências Sociais, 8., 16-18 set., Coimbra. Anais eletrônicos... In www.unb.com.br/ih/his/gefem Acesso em 07.Abr.2013.

DANIELS, Mark (2016). A história da mitologia para quem tem pressa. Heloísa Leal (Trad.). Rio de Janeiro: Valentina.

HALL, Stuart (2005). A identidade cultural na pós-modernidade. Thomaz Tadeu da Silva, Guacira Lopes Louro (Trad.). 10.ed. Rio de Janeiro: DP\&A. 
(2003). Da diáspora: Identidades e mediações culturais. Adelaine La Guardia Resende et al (Trad.). Belo Horizonte: Editora UFMG. 1a reimpressão.

ILOT, Sarah; BUCKLEY, Chloe (2016). "“Fragmenting and becoming double": Supplementary twins and abject bodies in Helen Oyeyemi's The Icarus Girl". The Journal of Commonwealth Literature, 51, 3.ed, 402-415. In http://journals.sagepub.com/doi/abs/10.1177/0021989414563999 Acesso em 01.Jan.2018.

LUNDELL, Ase (2010). “"Jess-who-wasn't-Jess": Double Consciousness and Identity Construction in Helen Oyeyemi's The Icarus Girl". Karlstad University. Faculty of Arts and Education. In http://www.diva-portal. org/smash/record.jsf?pid=diva2\%3A344191\&dswid=9340 Acesso em 28.Dez.2017.

NAYYAR, Nasir Abbas (2017). "Displacement in literature". The News on Sunday, 26 mar. In http://tns.thenews.com.pk/displacement-literature/\#. Wg2LBbBrzlU Acesso em 16.Nov.2017.

OUELLET, Pierre (2012). As palavras migratórias [L'éspirit migrateur]. Luciano P. Moraes (Trad.). Cadernos PPGL/Furg, Rio Grande, 7, jun. (Série Traduções).

OYEYEMI, Helen (2006). A menina Ícaro. Adalgisa Campos da Silva (Trad.). Rio de Janeiro: Intrínseca.

(2006b). The Icarus girl. New York: Anchor Books.

ROCHA, Ana Paula F. da (2010). "Identidade e migração". Revista Interdisciplinar da Mobilidade Urbana, Brasília, Ano XVIII, 34, 240-243, jan./jun. In http://www.csem.org.br/remhu/index.php/remhu/article/ viewFile/221/204 Acesso em 24.Nov.2017.

RODRIGUES, Sara Novaes (2016). "Lugar, localização". In: COSER, Stelamaris. (Org). Viagens, deslocamentos, espaços: conceitos críticos. Vitória: EDUFES. p.202-209.

SILVA, Denise Almeida (2016). "Casa, lar". In: COSER, Stelamaris. (Org). Viagens, deslocamentos, espaços: conceitos críticos. Vitória: EDUFES. p.34-41. 
STOUCK, Jordan (2011). "Abjecting Hybridity in Helen Oyeyemi's The Icarus Girl. ARIEL": A Review of International English Literature. 4(2), 89-112. In https://journalhosting.ucalgary.ca/index.php/ariel/article/ viewFile/35074/28965 Acesso em 25.Jan.2018.

THE COMMONWEALTH (2017). Nigeria: history. In http:// thecommonwealth.org/our-member-countries/nigeria/history Acesso em 21.Dez.2017.

Diego Bonatti é Mestrando em Letras, área de concentração - Póscolonialismo e Identidades pela UFRGS. Bolsista CAPES. E-mail: diego. bonatti@bol.com.br

Denise Almeida Silva é Doutora em Letras pela UFRGS. Docente da URI, Câmpus Frederico Westphalen, onde atua no PPGL - Mestrado em Letras - e na graduação. Organizou e/ou co-organizou, dentre outros, os volumes Pensando as Américas: narrativas e violência (2016), Para ler com prazer: proposições didáticas para o ensino da literatura africana, afro-brasileira e indígena em sala de aula (2015), Poéticas do espaço, geografias simbólicas (2013) e Literatura, história, etnicidade e educação: estudos nos contextos afro-brasileiro, africano e da diáspora africana (2011); é, também, autora de capítulos de livros e artigos em periódicos nacionais e estrangeiros. Integra o GT Relações Literárias Interamericanas, da ANPOLL. E-mail: dnsalmeidasilva@gmail.com 